\title{
Effect of Nursing Guidelines on Patients Undergoing Inguinal Hernia Repair Outcomes.
}

\author{
Hasnaa Talat Fawzy , Hala Mohammed Ghanem, Mohammed Bakr Mohammed \& Asmaa Sayed abd \\ Almageed
}

(B. SC. Nursing), Head nurse at Dairut General Hospital, Assiut, Egypt. Assistant Professor, Medical-Surgical Nursing, Faculty of Nursing, Assiut, University, Assiut, Egypt.

Lecturer, of General Surgery, Faculty of Medicine, Assiut University, Assiut, Egypt.

Lecturer, of Medical-Surgical Nursing, Faculty of Nursing, Assiut University, Assiut, Egypt.

\begin{abstract}
Inguinal hernia is a common type of hernia in which a loop of the intestine protrudes directly through a weak area of the abdominal wall in the groin region. This study aimed to assess the effect of nursing guidelines on patients undergoing inguinal hernia repair outcomes. A study was conducted in the general surgical departments at Assiut University Hospital. A consecutive sample of (60) patients was obtained. This sample was divided into study and control group (30) each. Tools utilized for data collection were interview questionnaire sheet and patients' evaluation sheet. Results showed that all the studied patients were male, aged above (30) years, married, manual workers and smokers. The level of patients' knowledge in study and control group preoperative was unsatisfactory (100\%) while before discharge level of knowledge for study group was satisfactory $(67.7 \%)$, also the level of complications decreased in study group than in control group. Conclusion: level of knowledge for patients who take designed nursing guidelines was higher than who didn't take any designed nursing guidelines also level of complications was lower in study group. Recommendation: each patient is given booklet include designed nursing guidelines about inguinal hernia disease and surgery .
\end{abstract}

Key words: Designed Nursing Guidelines; Inguinal Hernia Repair \& Patient's Outcomes.

\section{Introduction}

Inguinal hernia is a common type of hernia in which a loop of the intestine protrudes directly through a weak area of the abdominal wall in the groin region. (The groin is the area between abdomen and thigh). (Lunanske, 2016).

There are two types of inguinal hernia: indirect inguinal hernia, which are caused by a defect in the abdominal wall that is congenital, or acquired and direct inguinal hernia which usually occur only in male adults and are caused by a weakness in the muscles of the abdominal wall that develops over time. (Nicks, 2014).

Although the incidence and prevalence worldwide is unknown, it is estimated that over 20 million procedures for inguinal hernia are performed each year. In USA there are about 500,000 new cases of inguinal hernia each year. (Fitzgibbons, 2007) In USA 15 per 1000 population have inguinal hernia and 800,000 procedures are performed annually to repair it. Richard Burnley (2012) In the Middle East it is difficult to estimate incidence and prevalence of inguinal hernia. In 2008, it was estimated that in Egypt about 240,000 patients have inguinal hernia. (Menon, 2008) In Assiut University hospital through the year 2014, it was found that there were 400 patients performed surgical hernia repair. (Assiut University Hospital Recordes, 2014).
There is a number of factors that contribute to inguinal hernia formation which include aging, gender (male more than female), obesity, pregnancy, heavy lifting, smoking, chronic cough, frequent constipation, straining with defecation or urination, ascites, peritoneal dialysis, chronic obstructive pulmonary disease (COPD), cardiac disease and family history of hernias.(Akbulut et al., 2010).

The first sign of an inguinal hernia is a small bulge on one or, rarely, on both sides of the groin. The bulge may increase in size over time and usually disappears when lying down. There is also other signs and symptoms may appear including discomfort or pain in the groin especially when straining, lifting, coughing, or exercising that improves when resting, feelings such as weakness, heaviness, burning, or aching in the groin, a swollen or an enlarged scrotum in men or boys. (Simons et al., 2009).

If inguinal hernia is not treated well, complications may occur. It may be turned to irreducible inguinal hernia which means failure of returning contents of the sac back into the abdomen, inflammation of the hernia contents, hydrocele of the hernia sac, incarceration, intestinal obstruction, strangulation (When an incarcerated hernia is not treated, the blood supply to the contents may become obstructed, causing "strangulation" of the contents). This is an 
emergency situation that is if not treated it can cause death. (Jeyarajah \& Harford 2010).

The diagnosis of inguinal hernia is usually based on patient medical history, family history and a physical exam. Diagnostic investigations such as ultrasound and CT scans are not usually needed to diagnose an inguinal hernia unless if there is strangulation or incarceration. Other investigations may be needed to evaluate the status of any current health problems such as lung, heart or bleeding problems. A urine test may be done to rule out a urinary tract infection. A urinary tract infection or kidney stone may cause pain in the groin that can be mistaken for hernia pain. Surgery is the only treatment for inguinal hernia. (Sherman, 2010) and (Galal et al, 2016).

Complications that may occur after the surgery include wound seroma/hematoma, urinary retention, bladder injury, and superficial wound infection. while complications that occur later following hernia repair include persistent groin pain and post-herniorrhaphy neuralagia, testicular complications, deep wound/mesh infection, recurrent hernia, and mesh migration and erosion. (Matthews 2007).

People cannot prevent the weakness in the abdominal wall that causes inguinal hernias. However, people may be able to prevent inguinal hernias by maintaining a healthy weight and stop smoking. People can keep inguinal hernias from getting worse or keep inguinal hernias from recurring after surgery by avoiding heavy lifting, using the legs not the back when lifting objects, preventing constipation and straining during bowel movements, maintaining a healthy weight and stop smoking. (Simons et al., 2009).

So the nurse have a role to reduce occurring of these complications. The nurse should provide care to the patient preoperatively by preparing patient to surgery, providing him with all information about this condition, the surgical procedure and it's complications also she should provide care to the patient, postoperative care beginning with deep breathing exercise, using ice packs to reduce swelling of the scrotum. The operation is a day case surgery so the most important role of the nurse is in providing guidelines to the patient to follow at home in caring of the wound and how to change dressing and to report any symptoms of infection including itching, swelling, fever or having difficulty in urination. Also the nurse should advise the patient when to return to their normal daily life activities.(Rothrock \& Clark, 2010).

\section{Significance of the study}

From the researcher's clinical experience it has been observed that patients undergoing inguinal hernia repair need knowledge about surgery and also need to know how to deal postoperatively with the surgery. In the Middle East it is difficult to estimate incidence and prevalence of inguinal hernia. In 2005, it was estimated that in Egypt about 240,000 patients have inguinal hernia. In Assiut University hospital through year 2014, it was found that there were 400 patients performed inguinal hernia repair and that is according to Assiut University hospital records.

\section{The aim of the study}

The aim of this study was to assess the effect of nursing guidelines on patients undergoing inguinal hernia repair through;

- Assessing patient's knowledge about inguinal hernia repair.

- Developing nursing guidelines for patients undergoing inguinal hernia repair based on need assessment.

- Evaluating effect of nursing guidelines on patient's outcomes.

Hypothesis

Nursing guidelines will have a positive effect on patients undergoing inguinal hernia repair regarding their knowledge and postoperative complications.

\section{Subjects \& Method}

\section{Research design}

Quasi-experimental design was utilized in this study. Setting of the study

The study was conducted in the general surgical departments at Assiut University hospital.

\section{Study variables}

The independent variable in this study was the developed nursing guidelines for patients undergoing inguinal hernia repair, while the dependent variables were the patients' knowledge as well as the outcomes of patients undergoing inguinal hernia repair.

\section{Study subjects}

\section{Sample}

A purposive sample of (60) adult male patients who are admitted in general surgical departments was obtained. Those patients were divided equally into two groups, study and control group (30) patient for each. Those patients were fulfilling the following criteria:

Inclusive criteria

- Adult conscious patients.

- Male patients.

- Patients free from chronic illness.

Study tools

There are three tools were utilized to collect data for this study: 
Tool I: "Interview questionnaire sheet" for patients:

Interview questionnaire sheet was developed by the researcher, after extensive review of the relevant literature and consulting expertise in this area, it was designed in Arabic language.(Annex I)

The interview questionnaire sheet was consisted of four parts as the following:

Part I: It includes the demographic characteristics (e.g., age, occupation, marital status, level of education, residence, smoking and passive smokers).

Part II: It is used to assess patient s knowledge about inguinal hernia (definition, cause, contributing factors, symptoms, methods of treatment, and complications of inguinal hernia) and about inguinal hernia repair (definition of inguinal hernia repair, diagnostic study, types of anesthesia, and complications of inguinal hernia repair). The second part was assessed twice pre and post the operation and after given the patient the developed guidelines in the study group.

\section{Scoring system}

The interview questionnaire sheet (part II) was administered by the researcher to the patients for answering all its components, the total number of questions was (25). The total number of score was (62). Each right answer was given one score and zero for wrong answer, definition given two score because it is divided into two parts. Those who obtained less than $60 \%$ were considered unsatisfactory level while those who obtained more than $60 \%$ were considered satisfactory level.

Nursing guidelines for patients undergoing inguinal hernia repair:

The content of nursing guidelines were developed by the researcher based on reviewing the current national and international literature to maintain health of patients and reduce postoperative complications as well as the patient's needs which were identified after assessing their knowledge. Nursing guidelines included: preoperative care, postoperative care and home instructions.

Tool II:- "Patients' evaluation sheet"

This tool was designed by the researcher to assess the outcomes of patients undergoing inguinal hernia repair including postoperative complications that might develop related to the inguinal hernia repair (e.g. pain, bleeding, infection at the wound site, swelling of the scrotum, groin numbness, bruising, hematoma, seroma formation at the surgery site, orchitis and difficulty during urination. The evaluation sheet applied by the researcher before patient's discharge. (Annex II).

\section{Methods of data collection Ethical approval}

- An official permission to conduct the study was obtained by the researcher from the responsible hospital authorities of the general surgical departments at Assiut University Hospital. At initial interview, each patient was informed with the purpose of the study. The investigator emphasized that the participation is voluntary and confidentially and anonymity of subjects will be assured through coding of all data.

- This study approved by research ethical committee of faculty of nursing at Assiut University.

\section{Data Collection}

- A review of current and past, local and international related literature in the various aspects of the problems using books, articles, periodicals, and magazines was done. The purposed study setting was assessed for the numbers of patients in the general surgical departments at Assiut University Hospital.

- A pilot study was implemented on $10 \%$ of the sample. The purpose of this pilot study was of 2 folds: first to ensure the clarity of designated study tools. Second, to examine the utility of the designed tools and identify any difficulties or problems needed to be handled before receiving it.

- Confidentiality of the data was asserted. The aim of the study was explained to patients by the researcher. The right to refuse to participate in the study was emphasized to the patients.

- The researcher collected the data from patients by receiving tool (I \&II).

- Length of time was not exactly detectable, because patients are different in their conditions and ability of understanding. One of the family members was present in the session.

\section{Content validity of the data collection tools}

Panel of five experts to test the content validity of the tools was including 3 lecturer of Medical-Surgical Nursing, Adult Nursing Department from Assiut University and 2 physicians in General Surgery Department at Assiut University Hospital, they reviewed the tools for relevance, comprehensiveness, understanding and applicability for its purpose. Minor modifications were required. Then final form of the tool was designed and tested for reliability by using internal consistency for the tools. Experts in fields of medicine and nursing checked the content validity and reliability of the tools and corrections were carried out accordingly Procedure

An official letter was issued from the Dean of the Faculty of Nursing to the Head of the General 
Surgical departments soliciting the necessary approval to conduct the present research.

Once permission was granted to proceed with the proposed study, the investigator initiated data collection.

Data were collected from general surgical departments at Assiut University Hospital during the period from May /2015 to February/2016. The tools filled through interviewing. This study was carried out at morning and afternoon shifts.

Names of patients who are admitted to general surgical departments in Assuit University Hospital were obtained from the head nurses of the departments who helped the researcher work both during data collection and during patients care. As well an official permission from the patients was granted. Then patients were divided into both control and study group.

The study and control groups were visited by investigator to initiate line of communication, explain the nature and purpose of the study and fill out the first tool (pre-test). The control group were exposed to routine nursing care, while the study group were exposed to the developed nursing guidelines. Then demonstration and return demonstration were done about preoperative care, postoperative care and home instructions.

Post-test was done for the patients in the study group using the same tool I while tool

II (patient's evaluation sheet) was applied to the both study and control group before discharge.

\section{Statistical analysis}

A data entry file, using EXCEL 2007 program, was prepared. Data was analyzed using SPSS (version 19). The frequencies, percentages, mean and standard deviation were computed. Chi-square test was used to compare quantitative variables between groups. Mann-Whitney test was used as the test of significance to compare quantitative data between groups. Spearman correlation was done to measure correlation between quantitative variables.

\section{Results}

Table (1): Comparison between the study and control groups as regard demographic variables.

\begin{tabular}{|c|c|c|c|c|c|}
\hline \multirow{2}{*}{ Variables } & \multicolumn{2}{|c|}{ Study $(n=30)$} & \multicolumn{2}{|c|}{ Control(n= 30) } & \multirow{2}{*}{ P-value } \\
\hline & No. & $\%$ & No. & $\%$ & \\
\hline \multicolumn{5}{|l|}{ Age: (years) } & \multirow{3}{*}{0.080} \\
\hline$<30$ years & 11 & 36.7 & 5 & 16.7 & \\
\hline$\geq 30$ years & 19 & 63.3 & 25 & 83.3 & \\
\hline \multicolumn{5}{|l|}{ Occupational status } & \multirow{3}{*}{0.136} \\
\hline Office work & 5 & 16.7 & 10 & 33.3 & \\
\hline Manual worker & 25 & 83.3 & 20 & 66.7 & \\
\hline \multicolumn{5}{|l|}{ Marital status } & \multirow{4}{*}{0.099} \\
\hline Single & 7 & 23.3 & 3 & 10.0 & \\
\hline Married & 23 & 76.7 & 24 & 80.0 & \\
\hline Widow & 0 & 0.0 & 3 & 10.0 & \\
\hline \multicolumn{5}{|l|}{ Level of education } & \multirow{6}{*}{0.077} \\
\hline Illiterate & 9 & 30.0 & 18 & 60.0 & \\
\hline Read and write & 9 & 30.0 & 5 & 16.7 & \\
\hline Primary school & 3 & 10.0 & 1 & 3.3 & \\
\hline Secondary school & 8 & 26.7 & 3 & 10.0 & \\
\hline High school & 1 & 3.3 & 3 & 10.0 & \\
\hline \multicolumn{5}{|l|}{ Residence } & \multirow{3}{*}{0.222} \\
\hline Urban & 9 & 30.0 & 5 & 16.7 & \\
\hline Rural & 21 & 70.0 & 25 & 83.3 & \\
\hline \multicolumn{5}{|l|}{ Smoking } & \multirow{3}{*}{0.426} \\
\hline Smoker & 20 & 66.7 & 17 & 56.7 & \\
\hline Non-smoker & 10 & 33.3 & 13 & 43.3 & \\
\hline \multicolumn{5}{|c|}{ Sitting with smokers in home or work: (passive smokers) } & \multirow{3}{*}{$0.028 *$} \\
\hline Yes & 27 & 90.0 & 20 & 66.7 & \\
\hline No & 3 & 10.0 & 10 & 33.3 & \\
\hline
\end{tabular}

Statistical significant difference $(P<0.05)$ 
Table (2): Comparison between the mean knowledge scores obtained by study and control group about inguinal hernia as a disease and it's surgical management.

\begin{tabular}{|c|c|c|c|c|c|}
\hline \multirow{3}{*}{ Variables } & \multicolumn{2}{|c|}{ Study } & \multirow{2}{*}{$\begin{array}{c}\text { Control } \\
(n=30)\end{array}$} & \multirow{3}{*}{ P-value ${ }^{1}$} & \multirow{3}{*}{ P-value ${ }^{2}$} \\
\hline & \multirow{2}{*}{$\begin{array}{c}\begin{array}{c}\text { Preoperative } \\
(\mathbf{n}=\mathbf{3 0})\end{array} \\
\text { Mean } \pm \text { SD } \\
\end{array}$} & \multirow{2}{*}{$\begin{array}{c}\begin{array}{c}\text { Before discharge } \\
(\mathrm{n}=30)\end{array} \\
\text { Mean } \pm \text { SD }\end{array}$} & & & \\
\hline & & & Mean \pm SD & & \\
\hline Meaning of inguinal hernia & $0.07 \pm 0.25$ & $1.30 \pm 0.60$ & $0.13 \pm 0.35$ & $0.000 *$ & 0.393 \\
\hline Cause of inguinal hernia & $0.00 \pm 0.00$ & $0.43 \pm 0.50$ & $0.03 \pm 0.18$ & $0.000^{*}$ & 0.317 \\
\hline $\begin{array}{l}\text { Factors or habits can lead to inguinal } \\
\text { hernia }\end{array}$ & $0.47 \pm 0.73$ & $2.20 \pm 1.06$ & $0.87 \pm 0.78$ & $0.000^{*}$ & 0.122 \\
\hline Symptoms of inguinal hernia & $1.70 \pm 0.65$ & $2.17 \pm 0.46$ & $1.77 \pm 0.68$ & $0.002 *$ & 0.713 \\
\hline Methods of treating inguinal hernia & $0.70 \pm 0.47$ & $1.00 \pm 0.00$ & $0.83 \pm 0.38$ & $0.001 *$ & 0.226 \\
\hline $\begin{array}{l}\text { Complications that may occur if inguinal } \\
\text { hernia is not repaired }\end{array}$ & $0.30 \pm 0.53$ & $1.80 \pm 0.61$ & $0.33 \pm 0.55$ & $0.000^{*}$ & 0.785 \\
\hline Tests should be done before the operation & $3.13 \pm 0.51$ & $3.70 \pm 0.47$ & $3.33 \pm 0.61$ & $0.000^{*}$ & 0.143 \\
\hline Types of anesthesia & $0.50 \pm 0.82$ & $1.87 \pm 0.43$ & $0.40 \pm 0.67$ & $0.000^{*}$ & 0.805 \\
\hline $\begin{array}{l}\text { Complications may occur after inguinal } \\
\text { hernia repair surgery }\end{array}$ & $0.40 \pm 0.67$ & $2.10 \pm 0.76$ & $0.30 \pm 0.47$ & $0.000^{*}$ & 0.721 \\
\hline
\end{tabular}

$\boldsymbol{P}$-value 1 : The relationship between pre-operative + before discharge tests in the study group.

$\boldsymbol{P}$-value 2: The relationship between the both groups in the preoperative test.

Table (3):- Comparison between level of knowledge of the study and control group about inguinal hernia disease and it's surgery using true and false questions.

\begin{tabular}{|c|c|c|c|c|c|c|c|c|}
\hline \multirow{3}{*}{ Variables } & \multicolumn{4}{|c|}{ Study } & \multirow{2}{*}{\multicolumn{2}{|c|}{$\begin{array}{c}\text { Control } \\
(n=30)\end{array}$}} & \multirow{3}{*}{ P-value ${ }^{1}$} & \multirow{3}{*}{ P-value ${ }^{2}$} \\
\hline & \multicolumn{2}{|c|}{$\begin{array}{l}\text { Preoperative } \\
\quad(\mathbf{n}=\mathbf{3 0})\end{array}$} & \multicolumn{2}{|c|}{$\begin{array}{c}\text { Before } \\
\text { discharge } \\
(\mathbf{n}=\mathbf{3 0})\end{array}$} & & & & \\
\hline & No. & $\%$ & No. & $\%$ & No. & $\%$ & & \\
\hline \multicolumn{7}{|c|}{ It is necessary that the patient trying to reduce the weight before the operation } & \multirow{3}{*}{$0.000^{*}$} & \multirow{3}{*}{0.121} \\
\hline False & 13 & 43.3 & 1 & 3.3 & 19 & 63.3 & & \\
\hline True & 17 & 56.7 & 29 & 96.7 & 11 & 36.7 & & \\
\hline \multicolumn{7}{|c|}{ Inguinal hernia is a disease transmitted genetically } & \multirow{3}{*}{0.573} & \multirow{3}{*}{0.067} \\
\hline False & 10 & 33.3 & 8 & 26.7 & 4 & 13.3 & & \\
\hline True & 20 & 66.7 & 22 & 73.3 & 26 & 86.7 & & \\
\hline \multicolumn{7}{|c|}{ It is possible for patient to disregard the hernia and lives without treating it } & \multirow{3}{*}{$0.031 *$} & \multirow{3}{*}{0.108} \\
\hline False & 6 & 20.0 & 0 & 0.0 & 1 & 3.3 & & \\
\hline True & 24 & 80.0 & 30 & 100.0 & 29 & 96.7 & & \\
\hline \multicolumn{7}{|c|}{ The only solution for the treatment of inguinal hernia is the surgery } & \multirow{3}{*}{0.313} & \multirow{3}{*}{0.313} \\
\hline False & 1 & 3.3 & 0 & 0.0 & 0 & 0.0 & & \\
\hline True & 29 & 96.7 & 30 & 100.0 & 30 & 100.0 & & \\
\hline \multicolumn{7}{|l|}{ Inguinal hernia may be recurrent } & \multirow{3}{*}{0.472} & \multirow{3}{*}{0.255} \\
\hline False & 2 & 6.7 & 0 & 0.0 & 6 & 20.0 & & \\
\hline True & 28 & 93.3 & 30 & 100.0 & 24 & 80.0 & & \\
\hline \multicolumn{7}{|c|}{ It is important for the patient to maintain his body weight after surgery } & \multirow{3}{*}{0.148} & \multirow{3}{*}{0.260} \\
\hline False & 7 & 23.3 & 2 & 6.7 & 11 & 36.7 & & \\
\hline True & 23 & 76.7 & 28 & 93.3 & 19 & 63.3 & & \\
\hline \multicolumn{7}{|c|}{ Patient can return to hard work two weeks after surgery } & \multirow{3}{*}{$0.001 *$} & \multirow{3}{*}{0.573} \\
\hline False & 10 & 33.3 & 0 & 0.0 & 8 & 26.7 & & \\
\hline True & 20 & 66.7 & 30 & 100.0 & 22 & 73.3 & & \\
\hline \multicolumn{7}{|c|}{ You must stop smoking at least 8 hours before the surgery } & \multirow{3}{*}{$0.024 *$} & \multirow{3}{*}{0.196} \\
\hline False & 13 & 43.3 & 5 & 16.7 & 18 & 60.0 & & \\
\hline True & 17 & 56.7 & 25 & 83.3 & 12 & 40.0 & & \\
\hline
\end{tabular}

P-value 1 : The relationship between pre-operative + before discharge tests in the study group.

$\boldsymbol{P}$-value 2: The relationship between the both groups in the preoperative test. 
Table (4): Comparison between the level of knowledge of the study and control group about pre, postoperative education and home guidelines.

\begin{tabular}{|c|c|c|c|c|c|c|c|c|}
\hline \multirow{3}{*}{ Variables } & \multicolumn{4}{|c|}{ Study } & \multirow{2}{*}{\multicolumn{2}{|c|}{$\begin{array}{c}\text { Control } \\
(n=30)\end{array}$}} & \multirow{3}{*}{$\underset{\text { value }^{1}}{\text { P- }}$} & \multirow{3}{*}{ P-value $^{2}$} \\
\hline & \multicolumn{2}{|c|}{$\begin{array}{l}\text { Preoperative } \\
\qquad(\mathbf{n}=\mathbf{3 0})\end{array}$} & \multicolumn{2}{|c|}{$\begin{array}{c}\text { Before } \\
\text { discharge } \\
(\mathbf{n}=30)\end{array}$} & & & & \\
\hline & No. & $\%$ & No. & $\%$ & No. & $\%$ & & \\
\hline \multicolumn{9}{|c|}{ Preparations that should be done before surgery } \\
\hline Don't know & 7 & 23.3 & 0 & 0.0 & 5 & 16.7 & $0.016^{*}$ & 0.519 \\
\hline $\begin{array}{l}\text { Stop smoking at least } 48 \text { hours before } \\
\text { the surgery }\end{array}$ & 0 & 0.0 & 9 & 30.0 & 3 & 10.0 & $0.004 *$ & 0.236 \\
\hline $\begin{array}{l}\text { Practice simple chest exercises before } \\
\text { the surgery }\end{array}$ & 0 & 0.0 & 23 & 76.7 & 0 & 0.0 & $0.000 *$ & -- \\
\hline $\begin{array}{l}\text { Taking all preoperative prescribed } \\
\text { medications }\end{array}$ & 0 & 0.0 & 11 & 36.7 & 6 & 20.0 & $0.000 *$ & $0.031 *$ \\
\hline Fasting 8 hours before the surgery & 23 & 76.7 & 29 & 96.7 & 25 & 83.3 & 0.058 & 0.519 \\
\hline \multicolumn{9}{|c|}{ Needs to be done immediately after surgery } \\
\hline Don't know & 29 & 96.7 & 0 & 0.0 & 29 & 96.7 & $0.000 *$ & -- \\
\hline $\begin{array}{l}\text { Start moving the feet and legs on bed } \\
\text { as soon as possible }\end{array}$ & 0 & 0.0 & 20 & 66.7 & 0 & 0.0 & $0.000^{*}$ & -- \\
\hline $\begin{array}{l}\text { Sitting on the bed or chair most of the } \\
\text { time }\end{array}$ & 0 & 0.0 & 17 & 56.7 & 0 & 0.0 & $0.000 *$ & -- \\
\hline $\begin{array}{l}\text { Doing deep breathing exercise every } \\
\text { hour }\end{array}$ & 0 & 0.0 & 14 & 46.7 & 0 & 0.0 & $0.000 *$ & -- \\
\hline Walking as soon as possible. & 1 & 3.3 & 23 & 76.7 & 1 & 3.3 & $0.000 *$ & -- \\
\hline Total smoking cessation. & 0 & 0.0 & 3 & 10.0 & 0 & 0.0 & 0.236 & -- \\
\hline $\begin{array}{l}\text { Doing mild exercises such as bending } \\
\text { the trunk over the legs in a standing } \\
\text { position }\end{array}$ & 0 & 0.0 & 3 & 10.0 & 0 & 0.0 & 0.236 & -- \\
\hline \multicolumn{9}{|c|}{ Guidelines must be followed after discharge } \\
\hline Don't know & 24 & 80.0 & 0 & 0.0 & 22 & 73.3 & $0.000 *$ & 0.542 \\
\hline Follow up and wound care & 3 & 10.0 & 24 & 80.0 & 5 & 16.7 & $0.000 *$ & 0.704 \\
\hline Regulating the day meals & 1 & 3.3 & 4 & 13.3 & 1 & 3.3 & 0.350 & -- \\
\hline $\begin{array}{l}\text { Taking prescribed medications at the } \\
\text { definite time }\end{array}$ & 1 & 3.3 & 15 & 60.0 & 1 & 3.3 & $0.000 *$ & -- \\
\hline Keep walking & 0 & 0.0 & 8 & 26.7 & 0 & 0.0 & $0.008^{*}$ & -- \\
\hline $\begin{array}{l}\text { Doing progressive muscle relaxation } \\
\text { and deep breathing exercises }\end{array}$ & 0 & 0.0 & 1 & 3.3 & 0 & 0.0 & 0.313 & -- \\
\hline Stop smoking & 0 & 0.0 & 4 & 13.3 & 1 & 3.3 & 0.121 & 0.313 \\
\hline $\begin{array}{l}\text { Increase intake of water daily and } \\
\text { eating fruits and vegetables }\end{array}$ & 0 & 0.0 & 20 & 66.7 & 1 & 3.3 & $0.000 *$ & -- \\
\hline $\begin{array}{l}\text { Avoid lifting heavy objects at least } 6 \\
\text { months after the surgery }\end{array}$ & 2 & 6.7 & 16 & 53.3 & 3 & 10.0 & $0.000 *$ & 0.640 \\
\hline
\end{tabular}

$\boldsymbol{P}$-value 1 : The relationship between pre-operative + before discharge tests in the study group.

$\boldsymbol{P}$-value 2: The relationship between the both groups in the preoperative test.

Table (5): Correlation between patients' knowledge score in study and control group and their demographic characteristics.

\begin{tabular}{|l|c|c|c|}
\hline \multirow{2}{*}{\multicolumn{2}{|c|}{ Study group }} & \multirow{2}{*}{ Control group } \\
\cline { 2 - 4 } & Preoperative & Before discharge & \\
\cline { 2 - 4 } & Mean \pm SD & Mean \pm SD & Mean \pm SD \\
\hline \multirow{2}{*}{ Age: (years) } & $12.55 \pm 2.88$ & $24.82 \pm 2.27$ & $15.60 \pm 3.78$ \\
\hline$<30$ years & $13.58 \pm 3.01$ & $23.58 \pm 2.09$ & $13.40 \pm 2.36$ \\
\hline$\geq 30$ years & 0.365 & 0.141 & 0.097 \\
\hline P-value & & \multicolumn{2}{|c|}{} \\
\hline
\end{tabular}




\begin{tabular}{|c|c|c|c|}
\hline & \multicolumn{2}{|c|}{ Study group } & \multirow{2}{*}{ Control group } \\
\hline & Preoperative & Before discharge & \\
\hline & Mean \pm SD & Mean \pm SD & Mean \pm SD \\
\hline \multicolumn{4}{|c|}{ Occupational status } \\
\hline Office work & $14.80 \pm 2.68$ & $24.00 \pm 1.58$ & $15.80 \pm 3.01$ \\
\hline Manual worker & $12.88 \pm 2.95$ & $24.04 \pm 2.34$ & $12.75 \pm 1.89$ \\
\hline P-value & 0.189 & 0.971 & $0.002 *$ \\
\hline \multicolumn{4}{|l|}{ Marital status } \\
\hline Single & $12.29 \pm 2.69$ & $24.43 \pm 2.30$ & $15.00 \pm 2.65$ \\
\hline Married & $13.48 \pm 3.03$ & $23.91 \pm 2.21$ & $13.67 \pm 2.63$ \\
\hline Widow & -- & -- & $13.33 \pm 4.04$ \\
\hline P-value & 0.358 & 0.597 & 0.707 \\
\hline \multicolumn{4}{|c|}{ Level of education } \\
\hline Illiterate & $11.67 \pm 2.12$ & $22.78 \pm 1.30$ & $12.83 \pm 2.04$ \\
\hline Literate & $13.86 \pm 3.05$ & $24.57 \pm 2.31$ & $15.17 \pm 3.04$ \\
\hline P-value & 0.061 & $0.039 *$ & $0.018^{*}$ \\
\hline \multicolumn{4}{|l|}{ Residence } \\
\hline Urban & $14.11 \pm 3.33$ & $23.22 \pm 1.72$ & $15.80 \pm 2.86$ \\
\hline Rural & $12.81 \pm 2.77$ & $24.38 \pm 2.33$ & $13.36 \pm 2.53$ \\
\hline P-value & 0.276 & 0.192 & 0.064 \\
\hline \multicolumn{4}{|l|}{ Smoking } \\
\hline Smoker & $13.30 \pm 3.10$ & $23.90 \pm 1.94$ & $14.59 \pm 3.06$ \\
\hline Non-smoker & $13.00 \pm 2.79$ & $24.30 \pm 2.75$ & $12.69 \pm 1.70$ \\
\hline$P$-value & 0.798 & 0.648 & 0.055 \\
\hline
\end{tabular}

Table (6): Comparison between study and control group regarding complications after surgery.

\begin{tabular}{|c|c|c|c|c|}
\hline \multirow[b]{2}{*}{ Variables } & \multicolumn{2}{|c|}{$\operatorname{Study}(n=30)$} & \multicolumn{2}{|c|}{ Control(n= 30) } \\
\hline & No. & $\%$ & No. & $\%$ \\
\hline Pain & 2 & 6.7 & 2 & 6.7 \\
\hline \multicolumn{5}{|l|}{ Bleeding } \\
\hline Internal bleeding & 0 & 0.0 & 0 & 0.0 \\
\hline External bleeding & 0 & 0.0 & 0 & 0.0 \\
\hline \multicolumn{5}{|l|}{ Infection at the wound site } \\
\hline Pain of the surgery site & 1 & 3.3 & 2 & 6.7 \\
\hline Bad odor & 0 & 0.0 & 1 & 3.3 \\
\hline Redness at the site & 1 & 3.3 & 1 & 3.3 \\
\hline Pus at the site & 0 & 0.0 & 2 & 6.7 \\
\hline Swelling of the scrotum & 0 & 0.0 & 0 & 0.0 \\
\hline Groin numbness & 0 & 0.0 & 0 & 0.0 \\
\hline \multicolumn{5}{|l|}{ Bruising } \\
\hline Pain of the surgery site & 0 & 0.0 & 0 & 0.0 \\
\hline Dark red color of the skin & 1 & 3.3 & 0 & 0.0 \\
\hline \multicolumn{5}{|l|}{ Hematoma } \\
\hline Pain of the surgery site & 0 & 0.0 & 0 & 0.0 \\
\hline A red/ blue color or the skin & 0 & 0.0 & 0 & 0.0 \\
\hline \multicolumn{5}{|l|}{ Seroma formation at the surgery site } \\
\hline Swelling & 1 & 3.3 & 1 & 3.3 \\
\hline A tumor like mass & 0 & 0.0 & 0 & 0.0 \\
\hline \multicolumn{5}{|l|}{ Orchitis } \\
\hline Pain & 0 & 0.0 & 0 & 0.0 \\
\hline Swelling of one or both testicles & 0 & 0.0 & 0 & 0.0 \\
\hline Fever & 0 & 0.0 & 0 & 0.0 \\
\hline Sensation of heaviness in the affected area & 0 & 0.0 & 0 & 0.0 \\
\hline Difficulty during urination & 0 & 0.0 & 0 & 0.0 \\
\hline
\end{tabular}


Table (1): This table shows that the majority of both study and control group were aged above 30 years old, married and manual workers. As regarding residence the majority of both study and control group were from rural areas and smokers with no statistical significant difference between the both group. The only statistical significant difference between both group was in the items related to sitting with smokers in home or work.

Table (2): This table shows that there was statistically significant difference between preoperative (pre-test) and before discharge (posttest) in the study group in all the items While both study and control group were symmetrical in preoperative with no statistical significant difference between them.

Table (3): This table shows that there was statistically significant difference between (preoperative) and (before discharge) knowledge in the following items (It is necessary that the patient is trying to reduce the weight before the operation, It is possible for the patient to disregard the hernia and lives without treating it, patient can return to hard work 2 weeks after surgery, you must stop smoking at least 8 hours before the surgery).

While both study and control group were symmetrical in preoperative with no statistical significant difference between them.

Table (4): This table shows that there was statistically significant difference between (preoperative) and before discharge in study group in most of the items. While there was only one statistical significant difference between the study and control group regard (Taking all preoperative medications).

Table (5): This table shows that there was statistical significant difference in two items (occupational status in control group, and level of education in both study and control group).

Table (6): This table shows that in the study group $(6.7 \%)$ complain of pain and $(3.3 \%)$ complain of infection at the wound site, bruising and seroma formation at the surgery site, while in control group $(6.7 \%)$ complain of pain and infection at the wound site.

\section{Discussion}

In agreement with the present study, Quintas et al., (2000) found that people of any age can develop inguinal hernias, indirect hernias can appear before age 30 but the direct hernias which are much more common appear in men older than age 40 because the muscles of the abdominal wall weaken with age and this agrees with our results in which $(73.3 \%)$ of patients were aged above 30 years.
The present study found that most of the patients in the study group (83.3\%) and control group (66.7\%) are manual workers this results agreed with Richardson, (2010) a cohort analysis study which found that the risk of inguinal hernia repair increased with increasing cumulative exposures to daily lifting activities (total loads, frequent heavy lifting) and prolonged standing or walking at work.

In our study, it was observed that the incidence of inguinal hernia is highest among the group engaged in hard manual work and this agrees with Fitzgibbons et al., (2005) which suggested that inguinal hernias appears to occur more frequently in heavy laborers.

Jones et al., (2001) in his study "Return to work after inguinal hernia repair" found that $(79 \%)$ of the patients were married males and this agree with our study in which married patients were $(78 \%)$ of the patients.

Jones et al., (2001) the study reported that (77\%) of the patients are college-educated patients and this disagree with our study in which only $(6.67 \%)$ were college-educated patients.

Read et al., (2002) reported that there is an association between cigarette smoking and groin hernias and this agrees with the current study in which the majority of the patients in control group $(56.7 \%)$ and study group $(66.7 \%)$ are smokers.

Mohamed et al., (2012) in his study "Evaluation of patient's understanding and recall of the consent process after open inguinal hernia repairs "found that $(67 \%)$ of the patients felt that the surgery is the only way for treating hernias while in our study $(85 \%)$ of patients believe that the surgery is the only way for treating inguinal hernia.

A similar study conducted in outpatients clinics at El- Demerdash Surgical Hospital at Ain Shams University by Hegazy et al., ( 2012) reported that patients had unsatisfactory level of knowledge about disease pre guidelines, and significant improvement in patients' knowledge regarding post and follow up assessment.

Moore, (1995) asserted that providing patient with the information required concerned with their condition, the surgery and the recovery improving their level of knowledge about self-care to prevent and manage post-surgical discomfort and to decrease / reduce hospital readmission and morbidity and mortality rate and this agree with our study results which show that there was improvement in the level of knowledge about disease and care in the study group after given the nursing guidelines.

As for laboratory investigations and diagnostic procedures that are necessary for diagnosis and evaluating the patient's medical condition and his readiness for surgery, it was noticed that there were 
no statistical significant difference between the study and control group. In addition, routine laboratory investigations was done for the majority of the patients in the both control and study groups and the necessary diagnostic procedures according to the patient's condition were performed.

As regard to patient's knowledge about, postoperative complications the present study showed that statistical significant difference between pre-test and post-test in study group. These results agreed with Thomas, (2012) who carried out a study to investigate the impact of a designed nursing teaching these study found a highly significant difference between levels of knowledge in pre-test and posttest.

In agreement with this, a study conducted by Hussan \& Mohamed, (2012) in the outpatient medicine clinics in El-nasr Health insurance and Zagazig University Hospitals reported that, the implementation of the nursing guidelines program led to significant improvements in patient knowledge at the post-test.

The present study showed that there was statistical significant difference between pre-test and post-test for study group regarding practices toward patient's activity. It included breathing and coughing exercise, early ambulation, leg exercise, pain control. This finding was supported by Kilber, (2012) who reported that all members of the health care team agree that consistent, early and frequent post-operative ambulation improves both patient and provider satisfaction and has decreased post-surgery paralytic ileus, improved patient progress and facilitated appropriate patient discharges.

According to Debacker et al., (2003) which recommended that nutritional information should be given to optimize wound healing, maintain ideal body weight and reduce cholesterol levels if elevated. They should also eat plenty of fresh fruit, vegetables and cereals and this agrees with our present study in which patients level of knowledge regarding nutrition pretest was none $(0.00 \%)$ while in post-test it was satisfactory $(66.6 \%)$.

The present study revealed that, before implementation of developed nursing guidelines, the patient did not have any background or information about preoperative, postoperative and discharge instructions about inguinal hernia repair. Post implementation there were significant improvement in patient's level of knowledge regarding inguinal hernia surgery preoperative, postoperative and discharge instructions.

Mohamed et al., (2012) reported that (67\%) of the patients answered right about avoid lifting heavy objects, and this agrees with our study in which
(53\%) of the patients answered right about avoid lifting heavy objects at least after six months.

Rosen et al., (2011) reported that the main results of his study revealed that patients who undergone a day case surgery may experience persistent symptoms and other discomfort, interfering with daily functions after surgery for up to three months so we should continue to develop new care plans and guidelines that may lead to less suffering for patients and this agree with our results which revealed that there was statistical significant difference between study and control group in the level of knowledge about disease and care needed

In a study by Shikh et al., (2009) 5\% of the patients developed surgical site infection, while Amid et al., (1996) reported less than $2 \%$ wound infection Gianeta et al., (1997) reported that $0.7 \%$ of the patients developed wound infection. In our study there were $(3.3 \%)$ of the study group developed infection at the wound site while $(6.7 \%)$ among the control group.

The current study showed that a great effect of developed nursing guidelines on minimizing the occurrence of postoperative wound infection for the study group. This may be related to the instructions that was given to patients including importance of using sterile dressing, supporting the wound during cough, early ambulation, balanced nutrition and the use of prophylactic antibiotics according to prescription. These results in the same line with (Van Dam, 2013) that wound assessment and drainage under aseptic technique can enhance wound healing process.

Koninger et al., (2004) reported that the incidence of chronic pain that occurs after inguinal hernia repair is ranged from 0.03 to $31 \%$ and this large range maybe reflects heterogeneity of surgical approaches and techniques, duration of follow up and the experience of the surgeon. This agrees with our results which reported that $(6.7 \%)$ of both groups complain of persistent pain after surgery.

In our study patients in study group have a higher level of postoperative recovery and this agrees with Louise et al., (2007) as in his study approved that the patients who received preoperative teaching have higher levels of recovery.

In this regard, Abdel hammed et al., (2012) supported these result when reporting that, a higher statistically significant difference between patient's knowledge score pre and post exposure to the nursing designed protocol conducted for myocardial infarction patients, and revealed that, there was significant statistical correlation between educational level and mean knowledge scores among both (control and study groups). Also this agree with my study results which show that there 
was statistically significant difference between patients' knowledge score pre and post exposure to the designed nursing guidelines.

After implementing of the developed nursing guidelines, the study group had a highly significant improvement than those of the control group in relation to all items of knowledge. In this respect, jennuifer (2002) \& charlson et al., (2006) found that, applying nursing intervention postoperatively plays a major role in patients' improvement in relation to knowledge and recovery.

The current study answered the research hypothesis, where the mean knowledge score of patients who received instructions about disease (inguinal hernia) and inguinal hernia surgery was higher than the mean knowledge scores of a control group also the incidence of postoperative complications was lower in patients who receive the developed nursing guidelines than those who didn't receive it. So the developed nursing guidelines affect positively on the patient level of knowledge and complications.

So, it can be concluded that results from this study and other studies strongly suggest that teaching should be approached in organized manner, under pinned by sound principles of teaching and learning using teaching plans where appropriate to ensure that no vital aspects are omitted. Also, patient who undergo inguinal hernia repair surgery need extensive teaching and counseling to promote recovery and avoid complications.

\section{Conclusions}

Based on the results of the present study, it can be concluded that, level of Knowledge about the disease, surgery and care for patient's undergoing inguinal hernia repair was higher than who didn't take any nursing guidelines. Also level of complications in patients who get nursing guidelines was slightly lower than those who didn't take any developed nursing guidelines.

\section{Recommendations}

Surgical inguinal hernia repair is one of the most commonly performed operative procedures so great care should be given to those patients.

- Pamphlets and simple illustration booklet should be available for illiterate patients.

- Each patient is given booklet include nursing guidelines about inguinal hernia disease, preparations before surgery, after surgery and home instructions.

- Establishment of health education program in general surgery departments at Assiut University
Hospital to provide health teaching for patients about such operation.

\section{References}

1- Lunanske K., (2016): the Random House Dictionary, $9^{\text {th }}$ ed., Random House inc.

2- Nicks B., (2014): Hernias. Medscape website. http://emedicine.medscape.com/article/775630 Updated April 21, 2014. Accessed April 23, 2014.

3- Fitzgibbons R., (2007): The mesh and the spermatic cord. In Recurrent Hernia, Edited by: Schumpelick V, Fitzgibbons RJ. Springer, Heidelberg; 2007:333-337.

4- Richard Burnley (2012):

http://online.epocrates.com/u/2942723/inguinal+herni a 2012 Dec: BMJ Content.

5- Menon A., (2008): Hernia reduction. eMedicine specialities, April 8, 2008, available at www.emedicinehealth.com/hernia/article_em.htm . Reviewed on 2013.

6- Akbulut S., Cakabay B., \& Sezgin A., (2010): A familial tendency for developing inguinal hernias: study of a single family. Hernia. 2010 Aug. 14(4):431-4. [Medline].

7- Ruhl C., \& Everhart J., (2007): Risk factors for inguinal hernia among adults in the US population. Am J Epidemiol. 2007 May 15. 165(10):1154-61. [Medline].

8- Simons M., Aufenacker T., \& Bay-Nielsen M., (2009): European Hernia Society guidelines on the treatment of inguinal hernia in adult patients. Hernia, 13 (4):343-403.

9- Rothrock J., \& Clark M., (2010): Alexander's Care of the patient in surgery repair of hernias, $14^{\text {th }}$ edition, Elsevir company, chapter 12 , Pp396418.

10-Jeyarajah R., \& Harford W., (2010): Sleisenger and Fordtran's Gastrointestinal and Liver Disease: Pathophysiology, Diagnosis \& Management. . In: Feldman M, Friedman LS, Brandt LJ, eds. 9th ed, Philadelphia: Elsevier Saunders; Chapter 24: Abdominal hernias and gastric volvulus, Vol., 1, Pp. 379-395.

11- Sherman V., (2010): Schwartz's Principles of Surgery, Inguinal hernias. In FC Brunicardi et al., eds., 9th ed., New York: McGraw-Hill Pp. 13051342.

12-Galal S., Mohsen A., \& Korashi E., (2016): Kasr El-Aini Introduction to surgery, $8^{\text {th }}$ ed, Tawfikia Cairo, vol. 2, chapter 41, Pp. 675-678.

13-Matthews R., Anthony T., Kim L., Wang J., Fitizigbbon R., Giobbe-Hurder A., Read D., Itani K., \& Neumayer L., (2007): Factors associated with postoperative complications and hernia recurrence for patients undergoing inguinal 
hernia repair. The American Journal of Surgery, Pp. 194:611.

14-Quintas M., Rodrigues C., Yoo J., \& Rodrigues Junior A., (2000): Age related changes in elastic fiber system of the interfoveolar ligament. Revista de Hospital das clinicas, 55(3):83-86.

15-Richardson D., (2010): Discrete time hazards models for occupational and environmental cohort analyses. Occupation. Environ Med 2010; 67:6771.

16-Fitzgibbons R., Filippi C., \& Quinn T., (2005): Inguinal hernias. In Brunicardi FC,Anderson DK, Billiar TR, Dunn DL,Hunter JG, editors. Shwartz's principles of surgery, $8^{\text {th }}$ edition. New York: Mc Graw Hill; 2005.p. 1353-1394.

17-Jones R., Richard E., Burney M., Peterson M., \& Christy B., (2001): Return to work after inguinal hernia repair, Journal of surgery, volume 129 , number 2, Pp. 128-135.

18-Read R., (2002): The role of proteaseantiprotease in the pathogenesis of hernia and abdominal aortic aneurysm in certain smokers. Post Grad Gen Surg 2002; 14.

19-Mohammed M., Sinha S., BEnham S., VitishSharma P., Loizides S. and Myint S., (2012): Evaluation of patient's understanding and recall of the consent process after inguinal hernia repairs, the international journal of surgery, 10:5-10.

20-Hegazy S., Ali Z., Mohamoud A., \& Abou-zeid A., (2012): Outcomes of Educational guidelines on Awareness and Self-Efficacy among patients with permanent colostomy, New York Science Journal 2014 Volume 7, No.3, Pp. 25-32.

21- Moore, S., (1995): A comparison of women's and men's symptoms during home recovery after coronary artery bypass surgery. Heart \& Lung, 24(6), 495-501.

22-Thomas S., (2012): A study to Evaluate the Effectiveness of the structured teaching program on Cataract and Eye care, in terms of knowledge and practice among patients those have undergoing cataract Surgery in Retina Institute of Karnataka, Bengaluru, Indian Streams Research Journal, Vol.2, Pp.10.

23- Hussan Z., \& Mohamed N., (2014): Effect of nursing guidelines for recently diagnosed hypertensive patient on expected clinical outcomes, Journal of Nursing Education and Practice, Vol. 5, No. 3, Pp. 1:11

24-Kibler, A., (2012): quality improvement project increases postoperative ambulation and decreases patient complications. Vol.112, No. 4 At internet available http://unmhospitalist.pbworks.com.

25-Debacker G., Ambrosioni E., \& Borch-Johnsen K., (2003): European guidelines in cardiovascular disease prevention in clinical practice. European
Journal of Cardiovascular Prevention and Rehabilitation 10 (4: suupl 1): 51-578.

26- Rosen I., (2011): Patients' Experiences of symptoms, discomfort and their impact on daily living following day surgery, proQuest, Pp. 161180.

27-Shaikh M., Abro A., Naz S., \& Shaikh S., (2009): outcomes of open mesh hernia repair: five year's experience at chandka Medical College Hospital Larkana. JLUMHS, 8(3):205-9.

28- Amid P., Lichtenstein I., \& Shulman A., (1996): Open" tension free" repair of inguinal hernias: the Lichtenstein technique. Eur J Surg. 1996: 162(6):447-53.

29-Ginetta E., de Cian F., Cuneo S., \& Friedman D., (1997): Hernia repair in elderly patients. $\mathrm{Br} \mathrm{J}$ Surg. 1997:84 (7):983-5.

30-Van Dam P., Verheyden G., Sugihara H., Trinh X., Herman Mussel V., Wults H., Verkinderen L., Hauspy J., Vermeulen P., \& Dirix L., (2013): A Dynamic clinical pathway for the treatment of patients with Early Breast Cancer is a tool for better cancer care : Implementation and Prospective Analysis Between 2002-2010, World Journal of Surgical Oncology;11 (70): 110.

31-Konninger A., (2004): Chronic pain following inguinal hernia repair surgery, European Journal of pain, 10, $263-270$.

32- Louise E., Fabbro C., \& Bulfone G., (2007): Impact of preoperative patient education on prevention of postoperative complications, Journal of Advanced Nursing, 24,843-852.

33-Abdelhammeed M., Mohamed W., Selomay Abd-Elsalam \& Zeghla H., El-Sayed., (2012): Impact of a Designed Nursing Intervention protocol on Myocardian Infarction patients Outcome at a selected University Hospital in Egypt. Journal of Biology, Agriculture and Health care, Vol 3, No 17, Pp. 25:35.

34-Jennifer O., (2002): Quality of live 12 months after coronary artery bypass graft surgery. Heart and Lung, 29 (6): 401- 410.

35-Charlson J., Johnson J., Frankin B., \& Vandelann R., (2006): Program Participation exercise adherence, cardiovascular outcomes and program cost of traditional versus modified cardiac rehabilitation. American Journal of Cardiology, (86): 17-23. 